Tsuyoshi Watanabe, Takashi Yamamura, Miwa Watanabe, Shinobu Yasuo,

Nobuhiro Nakao, Alistair Dawson, Shizufumi Ebihara and Takashi Yoshimura

Am J Physiol Regulatory Integrative Comp Physiol 292:568-572, 2007. doi:10.1152/ajpregu.00521.2006

You might find this additional information useful...

This article cites 32 articles, 19 of which you can access free at:

http://ajpregu.physiology.org/cgi/content/full/292/1/R568\#BIBL

Medline items on this article's topics can be found at http://highwire.stanford.edu/lists/artbytopic.dtl on the following topics:

Endocrinology .. Hypothalamus

Endocrinology .. Thyroid

Oncology .. Thyroid Hormones

Physiology .. Passeriformes

Veterinary Science .. Mammalia

Updated information and services including high-resolution figures, can be found at:

http://ajpregu.physiology.org/cgi/content/full/292/1/R568

Additional material and information about American Journal of Physiology - Regulatory, Integrative and Comparative Physiology can be found at:

http://www.the-aps.org/publications/ajpregu

This information is current as of September 20, 2007.

The American Journal of Physiology - Regulatory, Integrative and Comparative Physiology publishes original investigations that illuminate normal or abnormal regulation and integration of physiological mechanisms at all levels of biological organization, ranging from molecules to humans, including clinical investigations. It is published 12 times a year (monthly) by the American

Physiological Society, 9650 Rockville Pike, Bethesda MD 20814-3991. Copyright @ 2005 by the American Physiological Society. ISSN: 0363-6119, ESSN: 1522-1490. Visit our website at http://www.the-aps.org/. 


\title{
Hypothalamic expression of thyroid hormone-activating and -inactivating enzyme genes in relation to photorefractoriness in birds and mammals
}

\author{
Tsuyoshi Watanabe, ${ }^{1 *}$ Takashi Yamamura, ${ }^{1 *}$ Miwa Watanabe, ${ }^{1}$ Shinobu Yasuo, ${ }^{1}$ \\ Nobuhiro Nakao, ${ }^{1}$ Alistair Dawson, ${ }^{2}$ Shizufumi Ebihara, ${ }^{1}$ and Takashi Yoshimura ${ }^{1,3}$ \\ ${ }^{1}$ Division of Biomodeling, Graduate School of Bioagricultural Sciences and ${ }^{3}$ Institute for Advanced \\ Research, Nagoya University, Furo-cho, Chikusa-ku, Nagoya, Japan; and ${ }^{2}$ Centre for Ecology \\ and Hydrology, Monks Wood, Abbots Ripton, Huntingdon, Cambridgeshire, United Kingdom
}

Submitted 21 July 2006; accepted in final form 18 September 2006

\begin{abstract}
Watanabe T, Yamamura T, Watanabe M, Yasuo S, Nakao N, Dawson A, Ebihara S, Yoshimura T. Hypothalamic expression of thyroid hormone-activating and -inactivating enzyme genes in relation to photorefractoriness in birds and mammals. Am J Physiol Regul Integr Comp Physiol 292: R568-R572, 2007; doi:10.1152/ajpregu.00521.2006.-Photorefractoriness is the insensitivity of gonadal development to the stimulatory effects of long photoperiods in birds and to the inhibitory effects of short photoperiods in small mammals. Its molecular mechanism remains unknown. Recently, it has been shown that reciprocal expression of thyroid hormone-activating enzyme [type 2 deiodinase (Dio2)] and -inactivating enzyme [type 3 deiodinase (Dio3)] genes in the mediobasal hypothalamus is critical for photoperiodically induced gonadal growth. Since thyroid hormones are required not only for photoinduction, but also for the induction of photorefractoriness, we examined the expression of these genes in relation to photorefractoriness in birds and mammals. Transfer of birds to long photoperiods induced strong expression of Dio2. This was maintained in tree sparrow when they later became photorefractory, but decreased somewhat in quail. In hamsters, transfer to long photoperiods also induced strong expression of Dio2. High values were not maintained under long photoperiods, and, indeed, expression decreased at the same rate as in animals transferred to short photoperiods. There was no renewed expression of Dio 2 associated with testicular growth as animals became refractory to short photoperiods. Expression of Dio3 was high under short photoperiods and low under long photoperiods in all the animals examined, except for the short photoperiod-refractory hamsters. Our present study revealed complex regulation of deiodinase genes in the photoinduction and photorefractory processes in birds and mammals. These gene changes may be involved in the regulation of photorefractoriness, as well as photoinduction.
\end{abstract}

Eurasian tree sparrow; Japanese quail; Djungarian hamster

THE MAJORITY OF BIRD AND MAMMAL species living outside the tropics uses a changing photoperiod to time their breeding seasons, but the photoreceptive and neuroendocrine mechanisms involved differ markedly between them (10, 15). Also, the degree of gonadal regression outside the breeding season is greater in birds, which may be an adaptation to flight, and the duration of breeding seasons of birds tend to be more restricted and asymmetrical than those of mammals. Although the times of gonadal maturation and regression are controlled by photoperiod in both birds and mammals, the period of gonadal

* T. Watanabe and T. Yamamura contributed equally to this work.

Address for reprint requests and other correspondence: T. Yoshimura, Division of Biomodeling, Graduate School of Bioagricultural Sciences and Institute for Advanced Research, Nagoya Univ., Furo-cho, Chikusa-ku, Nagoya, 464-8601, Japan (e-mail: takashiy@agr.nagoya-u.ac.jp). maturation, the breeding season, is rarely symmetrical with the annual change in photoperiod. The asymmetry is caused by photorefractoriness.

Photorefractoriness is the switch from an active to an inactive reproductive state, or vice versa, that occurs apparently spontaneously at some stage during prolonged exposure to a particular photoperiod $(19,20)$. In the case of birds, transfer from a short to a long photoperiod initially induces gonadal maturation, but some time later gonadal regression occurs as birds become refractory to the long photoperiod $(8,10,28)$. Some species, e.g., Japanese quail (Coturnix japonica), do not show spontaneous gonadal regression but become predisposed to undergo regression when the photoperiod is reduced somewhat, but to a photoperiod still longer than earlier required to induce maturation. This is relative, as opposed to absolute, photorefractoriness (25). In the case of small mammals, such as hamsters, transfer from a short to a long photoperiod also induces immediate gonadal maturation, and subsequent transfer to a short photoperiod induces immediate regression. Photorefractoriness in mammals is the spontaneous renewed gonadal maturation that occurs later during prolonged exposure to a short photoperiod (18-20). Although the same term, photorefractoriness, is used for both phenomena, the process in mammals may be opposite to that in birds. Refractoriness to short photoperiods in mammals may be equivalent to the termination of photorefractoriness to long photoperiods in birds. Both occur during exposure to a short photoperiod and involve reactivation of the reproductive system. In birds this reactivation is characterized by renewed photosensitivity, but, unlike mammals, is not normally associated with spontaneous rapid gonadal maturation.

Recently, it has been shown that local activation of thyroid hormone in the mediobasal hypothalamus $(\mathrm{MBH})$ is critical for long photoperiod-induced testicular growth in Japanese quail $(32,35)$. Long photoperiods induce expression of type 2 deiodinase (Dio2) gene and reduce expression of type 3 deiodinase (Dio3) gene. Dio2 is the thyroid hormone-activating enzyme; it converts the prohormone thyroxine $\left(\mathrm{T}_{4}\right)$ into the bioactive form $\mathrm{T}_{3}$ by outer-ring deiodination. The inactivating enzyme (Dio3) converts both $\mathrm{T}_{4}$ and $\mathrm{T}_{3}$ into inactive metabolites reverse $T_{3}$ and $T_{2}$, respectively, by inner-ring deiodination. It is well established that thyroid hormones are involved not only in photoinduction, but also in photorefractoriness $(5$, 10). Removal of the thyroid gland blocks photorefractoriness

The costs of publication of this article were defrayed in part by the payment of page charges. The article must therefore be hereby marked "advertisement" in accordance with 18 U.S.C. Section 1734 solely to indicate this fact. 
in the European starling, American tree sparrow, European house sparrow, and Japanese quail $(6,11,16,23,27)$. In the present study, therefore, we examined expression of Dio2 and Dio3 in relation to photorefractoriness in Eurasian tree sparrows (Passer montanus), which show absolute photorefractoriness, and Japanese quail, which show relative photorefractoriness.

As is the case in birds, thyroid hormones are involved in the regulation of seasonal reproduction in mammals. Thyroidectomy blocks transition of seasonal reproduction in sheep (19, 20 ), and photoperiodic regulation of Dio2 is observed in the Djungarian hamster (Phodopus sungorus) and goat (Capra hircus) $(26,31)$. Moreover, in hamsters, Dio2 expression is suppressed by melatonin administration (26), and exogenous thyroid hormone administration elicits a long photoperiod response under short photoperiods (13). Although cDNA microarray analysis identified a class of genes encoding thyroxine-binding proteins whose expression is associated with refractoriness (21), a molecular mechanism for mammalian refractoriness remains elusive. Therefore, we examined expression of Dio2 and Dio3 in the hypothalamus of photostimulated and photorefractory hamsters.

\section{MATERIALS AND METHODS}

Animals and housing. Male tree sparrows were caught from the wild in Nagoya during August 2003. They were kept under 8 h light: $16 \mathrm{~h}$ dark (8L16D) condition for $3 \mathrm{mo}$ at $24 \pm 1{ }^{\circ} \mathrm{C}$ in light-tight boxes $(55 \times 210 \times 62 \mathrm{~cm})$. Male 4-wk-old Japanese quail were obtained from a local dealer and kept in the same conditions until $8 \mathrm{wk}$ old. Djungarian hamsters were kept in our colony under 14L10D conditions until weaning at $3 \mathrm{wk}$ old and then transferred into light-tight boxes. In the light-tight boxes, light was supplied by fluorescent lamps with a light intensity of 200 lux measured at the level of the animal's head. Food and water were provided ad libitum for all animals, and sunflower seeds were given once per week to hamsters. Animals were treated in accordance with the guidelines of Nagoya University.

Light schedules. Sparrows and quail were transferred from short photoperiods (8L16D) to long photoperiods (18L6D). Brains were collected before transfer ( $0 \mathrm{wk}$; photosensitive), $6 \mathrm{wk}$ after transfer (photostimulated), and $20 \mathrm{wk}$ after transfer (absolutely photorefractory in sparrows, relative photorefractory in quail). In each case, this was done at the midpoint of the light phase.

To examine the effects of long photoperiods, hamsters were moved to $8 \mathrm{~L} 16 \mathrm{D}$ after weaning to induce testicular regression as previously described (26). One group of animals was continuously kept under $8 \mathrm{~L} 16 \mathrm{D}$, and another group was transferred to $14 \mathrm{~L} 10 \mathrm{D}$ at $7 \mathrm{wk}$ of age. Brains were collected at 9 wk of age. To examine gene expression in refractory animals, hamsters were kept under 14L10D after weaning. When $7 \mathrm{wk}$ old, animals for the refractory group were transferred to 10L14D, and control animals were kept under 14L10D. Brains were collected (at the midpoint of the light phase) before transfer to 10L14D (0 wk; photostimulated), $6 \mathrm{wk}$ after transfer (gonadal regressed), and 27 wk after transfer (refractory).

In situ hybridization. In situ hybridization was carried out according to previous work (34). Antisense 45-oligomer oligonucleotide probes were labeled with $\left[{ }^{33} \mathrm{P}\right]$ deoxy-ATP (NEN Life Sciences, Boston, MA) using terminal deoxyribonucleotidyl transferase (Invitrogen Life Technologies): sparrow and quail Dio2, 5'-gatggttcagcctcaatgaatatcaagacggaaatacattctgta-3'; sparrow Dio3, 5'-ggatgatgtagagcctctcgaagtaggcaccgtaggcggcgctgg- $3^{\prime}$; quail Dio3, 5'-tctcctcetggatgacgtagagccgctcgaagtaggcgecgtagg-3'; hamster Dio2, 5' -tgcttgagtagaatgaccgagtcatagagcgecaggaagaggcag-3'; and hamster Dio3, 5'ctggtaaccgtcggggecacggectcctggtacatgatggtgcc- $3^{\prime}$. Coronal sections (20 $\mu \mathrm{m}$ thick) were prepared using a Cryostat (model CM3050S;
Leica, Nussloch, Germany). Hybridization was carried out overnight at $42^{\circ} \mathrm{C}$. After the glass slides were washed, they were air-dried and apposed to Biomax-XR film (Eastman Kodak, Rochester, NY) for 2 wk with ${ }^{14} \mathrm{C}$-labeled standards (American Radiolabeled Chemicals, St. Louis, MO). Relative optical densities were measured using a computerized image analysis system (MCID Imaging Research, St. Catharines, Canada) and were converted into relative radioactive values (nanocuries) using ${ }^{14} \mathrm{C}$-labeled standards. Specific hybridization signals were obtained by subtracting background values obtained from adjacent brain areas that did not exhibit a hybridization signal.

\section{RESULTS}

Expression of Dio2 and Dio3 in photorefractory birds. In sparrows, there was significant testicular growth $6 \mathrm{wk}$ after transfer to long photoperiods, followed by complete regression after $20 \mathrm{wk}$, as birds became absolutely photorefractory [oneway ANOVA, $F(2,9)=44.6, P<0.0001$, Fisher's least significant difference (LSD) post hoc test, $P<0.0001, n=$ 4](Fig. 1A). In contrast, in relative photorefractory quail, the increase in testis size after $6 \mathrm{wk}$ of photostimulation was maintained at $20 \mathrm{wk}$, as expected [one-way ANOVA, $F(2,11)=138.3, P<0.0001$; Fisher's LSD post hoc test, $P<$ $0.0001, n=4-5]$ (Fig. 1B).

Expression of Dio2 and Dio3 was observed in the basal tuberal hypothalamus, consisting of the infundibular nucleus and the median eminence in both sparrow and quail (Fig. 2, A and $B$ ). This is consistent with previous reports. In sparrows, expression of Dio2 was significantly increased 6 wk after transfer to long photoperiods, and this high expression was maintained at $20 \mathrm{wk}$ [one-way ANOVA, $F(2,10)=20.6, P<$ 0.0005; by Fisher's LSD post hoc test, $P<0.001, n=4$ or 5] (Fig. 2A). In quail, expression of Dio2 was also significantly increased $6 \mathrm{wk}$ after transfer to long photoperiods, but expression was somewhat attenuated at 20 wk [one-way ANOVA, $F(2,11)=63.5, P<0.0001$; Fisher's LSD post hoc test, $P<$ $0.005, n=4-5$ ] (Fig. 2B). These experiments were repeated using different series of animals with consistent results (data not shown). In contrast to Dio2, expression of Dio3 was high under short photoperiods ( $0 \mathrm{wk}$ ) but almost undetectable $6 \mathrm{wk}$ and $20 \mathrm{wk}$ after transfer to long photoperiods in both sparrow and quail [sparrow: one-way ANOVA, $F(2,10)=41.8, P<$ 0.0001, Fisher's LSD post hoc test, $P<0.0001, n=4-5$;
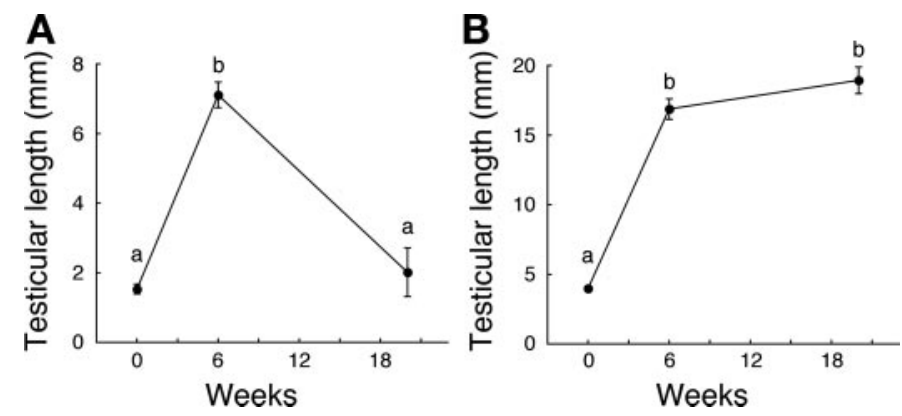

Fig. 1. Effect of long photoperiods on testicular length in absolute photorefractory Eurasian tree sparrow $(A)$ and relative photorefractory Japanese quail $(B)$. Testicular length was measured before transferring to long photoperiods ( 0 wk; photosensitive state), 6 wk after transfer to long photoperiods (photostimulatory state), and $20 \mathrm{wk}$ after transferred to long photoperiods (photorefractory state in sparrow). Values are means $\pm \operatorname{SE}(n=4-5)$. Different characters indicate significant differences [one-way ANOVA and Fisher's least significant difference (LSD) post hoc test]. 

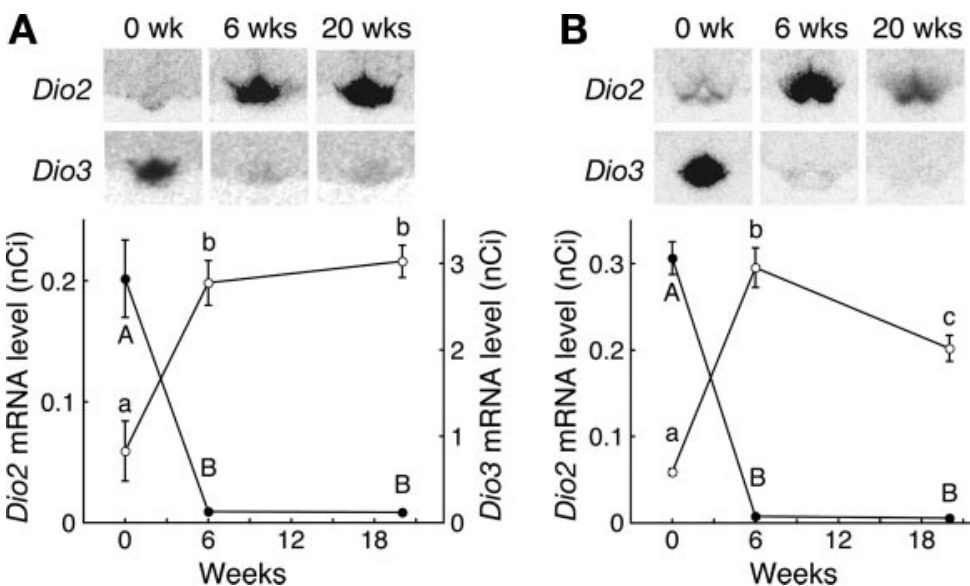

Fig. 2. Expression of thyroid hormone-activating (Dio2) and -inactivating (Dio3) enzyme genes in sparrows $(A)$ and quail (B). Top: representative autoradiograms for Dio2 and Dio3 expressions in the basal tuberal hypothalamus. Bottom: quantitative results of Dio2 (O) and Dio3 (•). Values are means \pm SE $(n=3-5)$. Different letters (lower case for Dio2 and upper case for Dio3) indicate significant differences (one-way ANOVA and Fisher's LSD post hoc test).

quail: $F(2,8)=209.2, P<0.0001$, Fisher's LSD post hoc test, $P<0.0001, n=3-4]$ (Fig. 2, $A$ and $B$ ).

Expression of Dio2 and Dio3 in long-day-stimulated and short-day-refractory hamsters. When hamsters were transferred from short to long photoperiods, testicular mass increased (Mann-Whitney $U$-test, $P<0.01, n=5$ ) (Fig. 3). When hamsters were transferred from long to short photoperiods, testicular mass was decreased at $6 \mathrm{wk}$ and then returned to long photoperiod values at $27 \mathrm{wk}$ as hamsters became refractory to short photoperiods. High testicular mass was maintained in animals that had been kept on long photoperiods [two-way ANOVA, $F(2,26)=55.3, P<0.0001$; MannWhitney $U$-test, $P<0.01, n=5-7$ ] (Fig. 3).

Dio2 expression was found in the ependymal cell layer lining the infralateral walls of the third ventricle and the cell-clear zone overlying the tuberoinfundibular sulcus, as previously described (Fig. 4A). Dio3 expression was observed only in the ependymal cell layer lining the infralateral walls of the third ventricle (Fig. 4B). When animals were transferred from short to long photoperiods, a significant increase in Dio2 expression and decrease in Dio3 expression were observed (Mann-Whitney $U$-test, $P<0.01, n=5$ ) (Fig. 4). Interestingly, when hamsters were maintained under long photoperiods continuously, expression of Dio2 decreased [one-way ANOVA, $F(3,16)=15.9, P<0.0001$, Fisher's LSD post hoc

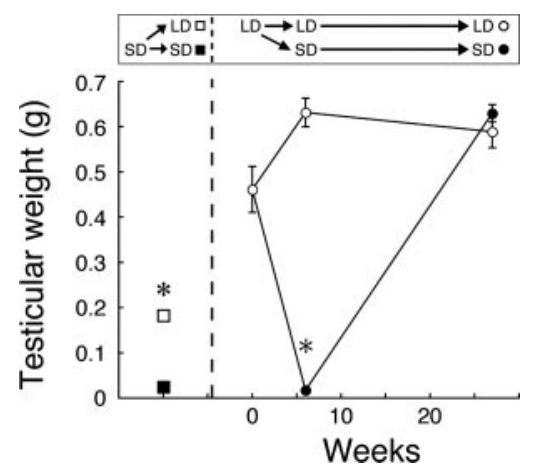

Fig. 3. Effect of different photoperiods on testicular weight in hamster. Left: animals were transferred from short (SD) to long (LD) photoperiods ( $\square$ ) or continuously kept under short photoperiods ( $\mathbf{\square})$ for $2 \mathrm{wk}$. In the right side of the graph, animals were transferred from long to short photoperiods (•) or continuously kept under long photoperiods $(\mathrm{O})$. Values are means $\pm \mathrm{SE}(n=$ 5-7). *Significant difference between the short photoperiod and long photoperiod groups (Mann-Whitney $U$-test). test, $P<0.05, n=5-7$ ] (Fig. $4 A$ ). When hamsters were transferred from long to short photoperiods, expression of Dio2 also decreased; there was no significant difference between long and short photoperiod animals [two-way ANOVA, $F(3,18)=0.712, P>0.5, n=5-7]$ (Fig. 4A). Expression of Dio3 was undetectable under long photoperiods. Strong expression of Dio3 was observed in hamsters shortly after transfer to short photoperiods, but this was not maintained; there was no expression of Dio3 in hamsters as they became refractory to short photoperiods [(two-way ANOVA for the comparison between $\mathrm{LD} \rightarrow \mathrm{SD}$ and $\mathrm{LD} \rightarrow \mathrm{LD}), F(2,26)=156.0, P<$ 0.0001; Mann-Whitney $U$-test, 6 wk: $P<0.01$ (asterisk); 27 wk: $P>0.8$; one-way ANOVA for the comparison among the SD group, $F(2,14)=63.9, P<0.0001$; Fisher's LSD post hoc test, $P<0.05, n=5-7$ ] (Fig. $4 B$ ).

\section{DISCUSSION}

In the present study, we examined expression of Dio2 and Dio3 in absolutely photorefractory Eurasian tree sparrows and in relative photorefractory Japanese quail. In these species, expression of Dio2 and Dio3 was directly related to photoperiod (i.e., high expression of Dio3 and low expression of Dio2 under short photoperiods and high expression of Dio2 and low expression of Dio3 under long photoperiods), but did not relate to gonadal status. Differences in reproductive state depend on the amplitude and frequency of pulsatile secretion of gonadotropin-releasing hormone $(\mathrm{GnRH})$. Unlike mammals, there is a profound physiological switch-off of the GnRH system in seasonally breeding birds (10), including sparrows (6). In absolutely photorefractory birds, a dramatic decline in hypothalamic GnRH content is observed by radioimmunoassay and immunocytochemistry, suggesting that the GnRH system is regulated at the level of synthesis, as well as secretion $(3,10$, 22). In contrast to species that become absolute photorefractory, relative photorefractory quail show no decline in hypothalamic GnRH (12). This suggests a fundamental difference between the mechanisms underlying the two forms of photorefractoriness (10).

Thyroid hormones are involved in both photoinduction and photorefractoriness. In the previous study, we observed seasonal morphological changes in the neuro-glial interaction between GnRH nerve terminals and glial endfeet in the median eminence of Japanese quail (29). Since these morphological changes were also caused by $\mathrm{T}_{3}$ administration, long-photope- 

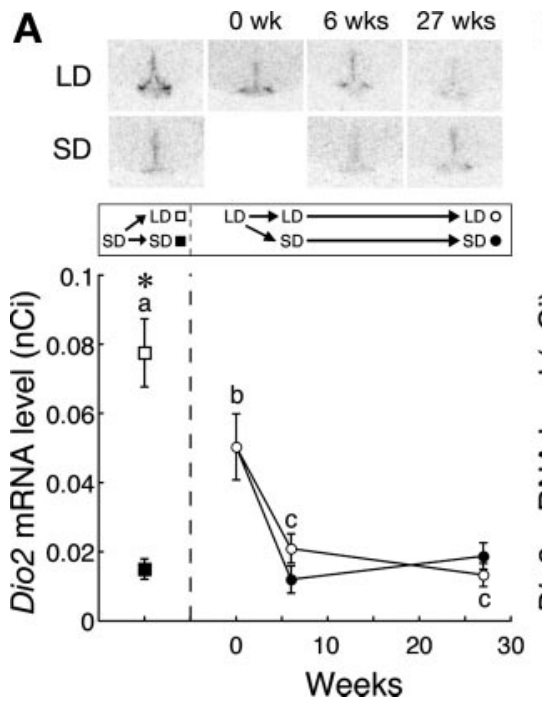

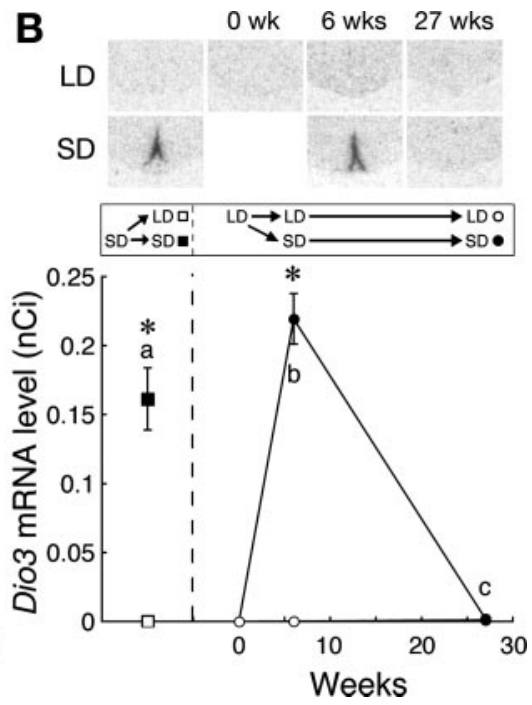

Fig. 4. Effect of different photoperiods on Dio2 (A) and Dio3 $(B)$ expression in hamsters. Representative autoradiograms are shown top. Quantitative results are shown bottom. Left: animals were transferred from short to long photoperiods ( $\square$ ) or continuously kept under short photoperiods (汭) for 2 wk. Right: animals were transferred from long to short photoperiods $(\bullet)$ or continuously kept under long photoperiods (O). Values are means $\pm \mathrm{SE}(n=5-7)$. Different characters indicate significant differences within the long photoperiod group $(A)$ and short photoperiod group $(B)$, respectively (one-way ANOVA and Fisher's LSD post hoc test). *Significant difference between the short and long photoperiod groups (Mann-Whitney $U$-test). riod-induced $\mathrm{T}_{4}$ to $\mathrm{T}_{3}$ conversion by Dio2 may regulate $\mathrm{GnRH}$ secretion in quail during photoinduction (30). Starlings and sparrows become photoperiodically blind following thyroidectomy $(5,6)$. In these species, prevention of photorefractoriness by thyroidectomy is associated with maintenance of high hypothalamic GnRH levels typical of photosensitive birds (6, 7,22 ) and thyroidectomy of photorefractory birds results in an increase in GnRH (9). These reports suggest that thyroid hormones are required to reduce $\mathrm{GnRH}$ synthesis during the photorefractory state, rather than a decrease in secretion. The maintenance of high expression of Dio2 and low expression of Dio3 as tree sparrows became photorefractory in the present study supports the idea that photorefractoriness is not due to an inhibition of $\mathrm{GnRH}$ secretion, i.e., a reversal of what happens during photostimulation. Rather, $\mathrm{T}_{3}$ may be involved in the long-photoperiod process leading to decreased GnRH synthesis. However, quail also maintained high expression of Dio2, although somewhat less than during photostimulation, as they became relatively photorefractory. Yet this is not associated with a decrease in hypothalamic stores of GnRH.

In short-day breeders, such as sheep and goats, thyroid hormones are required for the transition from estrus to anestrus in the spring. In the previous study, we found high expression of Dio2 in the hypothalamus of goats during this transition stage (31). As possible homologies between photorefractoriness in long-day birds and short-day mammals have been pointed out $(19,20)$, the present results also appear to suggest that the mechanism regulating short-day breeders and long-day breeders may not be so radically different as previously thought.

In the present study, we have also examined expression of Dio2 and Dio3 in Djungarian hamsters. Consistent with our previous report (26), we observed significant induction of Dio2 expression when transferred from short to long photoperiods. However, expression of Dio2 decreased when hamsters were continuously kept under long photoperiods. Barrett et al. (1) have reported that they failed to detect photoperiodic change of Dio2 expression in their Siberian hamster. In the present study, we did not find statistically significant difference in Dio2 expression between short and long photoperiod hamsters when we transferred animals from long to short photoperiods. This may explain the discrepancy between the results of our previous study and that of Barrett et al., because they examined expression of Dio2 in animals transferred from long to short photoperiods. Recently, Revel et al. (24) reported photoperiodic regulation of Dio2 in Syrian hamster (Mesocricetus auratus). In contrast to Djungarian hamsters, Dio2 expression remained elevated in the long photoperiod for at least $28 \mathrm{wk}$ in the Syrian hamsters. Although these two hamsters are known to be good photoperiodic models, differences in photoperiodic responses are reported $(4,14,17,33)$. Although both species exhibit gonadal regression when exposed to short photoperiods, they show opposite body weight changes (i.e., Djungarian hamsters lose weight, but Syrian hamsters gain weight following short photoperiod exposure) (2). In addition, puberty is apparently unaffected by the photoperiod in Syrian hamsters $(4,14)$, while it is highly affected by photoperiod in Djungarian hamsters $(17,33)$. Differences in Dio2 expression profiles may contribute to the different photoperiodic responses between the two hamsters.

In contrast to Dio2, marked increase in Dio3 expression was observed in short photoperiod hamsters. Since Dio3 metabolizes both prohormone $\mathrm{T}_{4}$ and bioactive $\mathrm{T}_{3}$, Dio3 may contribute to testicular regression when hamsters are transferred from long to short photoperiods. In short-day refractory hamsters, expression of Dio2 and Dio3 was undetectable. Consistent with the present results, a low level of Dio2 expression is reported in the short-day refractory Syrian hamster (24). It is of note that the expressions of a class of genes encoding thyroxine-binding proteins (TBPs; transthyretin, $\mathrm{T}_{4}$-binding globulin, and albumin) are downregulated and that $\mathrm{T}_{4}$ uptake was diminished in the hypothalamus of refractory Siberian hamsters (21). Although the molecular mechanism regulating refractoriness to short photoperiods in hamsters remains unknown, lack of expression of thyroid hormone-activating and -inactivating enzyme genes and TBPs may suggest that refractoriness to short photoperiods in hamsters is not thyroid dependent.

It has been known for several decades that thyroid hormones are involved in regulation of photorefractoriness $(6,11,16,23$, 27 ). Our present study revealed complex regulation of deiodinase genes in the photoinduction and photorefractory processes in birds and mammals. This is a first step toward understanding 
the molecular mechanism regulating photorefractoriness but many questions remain.

\section{ACKNOWLEDGMENTS}

We thank the Nagoya University Radioisotope Center for use of facilities.

\section{GRANTS}

This work was supported by the Program for Promotion of Basic Research Activities for Innovative Biosciences (to T. Yoshimura).

\section{REFERENCES}

1. Barrett P, Ross AW, Balik A, Littlewood PA, Mercer JG, Moar KM, Sallmen T, Kaslin J, Panula P, Schuhler S, Ebling FJ, Ubeaud C, Morgan PJ. Photoperiodic regulation of histamine $\mathrm{H} 3$ receptor and VGF messenger ribonucleic acid in the arcuate nucleus of the Siberian hamster. Endocrinology 146: 1930-1939, 2005.

2. Bartness TJ, Wade GN. Photoperiodic control of seasonal body weight cycles in hamsters. Neurosci Biobehav Rev 9: 599-612, 1985.

3. Bluhm CK, Schwabl H, Schwabl A, Perera A, Follett BK, Goldsmith AR, Gwinner E. Variation in hypothalamic gonadotrophin-releasing hormone content, plasma and pituitary LH, and in-vitro testosterone release in a long-distance migratory bird, the garden warbler (Sylvia borin), under constant photoperiods. J Endocrinol 128: 339-345, 1991.

4. Darrow JM, Davis FC, Elliott JA, Stetson MH, Turek FW, Menaker M. Influence of photoperiod on reproductive development in the golden hamster. Biol Reprod 22: 443-450, 1980.

5. Dawson A. Thyroidectomy progressively renders the reproductive system of starlings, Sturnus vulgaris, unresponsive to changes in daylength. $J$ Endocrinol 139: 51-55, 1993.

6. Dawson A. Thyroidectomy of house sparrows (Passer domesticus) prevents photo-induced testicular growth but not the increased hypothalamic gonadotrophin-releasing hormone. Gen Comp Endocrinol 110: 196-200, 1998.

7. Dawson A, Follett BK, Goldsmith AR, Nicholls TJ. Hypothalamic gonadotrophin-releasing hormone and pituitary and plasma FSH and prolactin during photostimulation and photorefractoriness in intact and thyroidectomized starlings (Sturnus vulgaris). J Endocrinol 105: 71-77, 1985.

8. Dawson A, Goldsmith AR. Prolactin and gonadotrophin secretion in wild starlings (Sturnus vulgaris) during the annual cycle and in relation to nesting, incubation and rearing young. Gen Comp Endocrinol 48: 213221, 1982.

9. Dawson A, Goldsmith AR, Nicholls TJ, Follett BK. Endocrine changes associated with the termination of photorefractoriness by short daylengths and thyroidectomy in starlings (Sturnus vulgaris). J Endocrinol 110: 73-79, 1986.

10. Dawson A, King VM, Bentley GE, Ball GF. Photoperiodic control of seasonality in birds. J Biol Rhythms 16: 365-380, 2001.

11. Follett BK, Nicholls TJ. Influences of thyroidectomy and thyroxine replacement on photoperiodically controlled reproduction in quail. $J$ Endocrinol 107: 211-221, 1985.

12. Foster RG, Panzica GC, Parry DM, Viglietti-Panzica C. Immunocytochemical studies on the LHRH system of the Japanese quail: influence by photoperiod and aspects of sexual differentiation. Cell Tissue Res 253: 327-335, 1988.

13. Freeman DA. Exogenous $T_{3}$ elicits long day reproductive responses in short-day housed Siberian hamsters (Abstract 181). 10th meeting of Society for Research on Biological Rhythms, Sandestin, FL, May 21-25, 2006.

14. Gaston S, Menaker M. Photoperiodic control of hamster testis. Science 158: 925-928, 1967

15. Goldman BD. Mammalian photoperiodic system: formal properties and neuroendocrine mechanisms of photoperiodic time measurement. $\mathrm{J}$ Biol Rhythms 16: 365-380, 2001.

16. Goldsmith AR, Nicholls TJ. Thyroidectomy prevents the development of photorefractoriness and the associated rise in plasma prolactin in starlings. Gen Comp Endocrinol 54: 256-263, 1984.
17. Hoffmann K. Effect of short photoperiods on puberty, growth and moult in the Djungarian hamster (Phodopus sungorus). J Reprod Fertil 54: 29-35, 1978.

18. Hoffmann K. Photoperiodism in vertebrates. In: Handbook of Behavioural Neuroendocrinology (4th ed.), edited by Aschloff J. New York: Plenum, 1981, p. 449-473.

19. Nicholls TJ, Follett BK, Goldsmith AR, Pearson H. Possible homologies between photorefractoriness in sheep and birds: the effect of thyroidectomy on the length of the ewe's breeding season. Reprod Nutr Dev 28: 375-385, 1988.

20. Nicholls TJ, Goldsmith AR, Dawson A. Photorefractoriness in birds and comparison with mammals. Physiol Rev 68:133-176, 1988.

21. Prendergast BJ, Mosinger B Jr, Kolattukudy PE, Nelson RJ. Hypothalamic gene expression in reproductively photoresponsive and photorefractory Siberian hamsters. Proc Natl Acad Sci USA 99: 16291-16296, 2002.

22. Reinert BD, Wilson FE. Thyroid dysfunction and thyroxine-dependent programming of photoinduced ovarian growth in American tree sparrows (Spizella arborea). Gen Comp Endocrinol 103: 71-81, 1996.

23. Reinert BD, Wilson FE. Effect of thyroxine $\left(\mathrm{T}_{4}\right)$ or triiodothyronine $\left(\mathrm{T}_{3}\right)$ replacement therapy on the programming of seasonal reproduction and postnuptial molt in thyroidectomized male American tree sparrows (Spizella arborea) exposed to long days. J Exp Zool 279: 367-376, 1997.

24. Revel FG, Saboureau M, Pevet P, Mikkelsen JD, Simonneaux V. Melatonin regulates type 2 deiodinase gene expression in the Syrian hamster. Endocrinology 147: 4680-4687, 2006.

25. Robinson JE, Follett BK. Photoperiodism in Japanese quail: the termination of seasonal breeding by photorefractoriness. Proc $R$ Soc Lond $B$ Biol Sci 215: 95-116, 1982.

26. Watanabe M, Yasuo S, Watanabe T, Yamamura T, Nakao N, Ebihara S, Yoshimura T. Photoperiodic regulation of type 2 deiodinase gene in Djungarian hamster: possible homologies between avian and mammalian photoperiodic regulation of reproduction. Endocrinology 145: 1546-1549, 2004.

27. Wieselthier AS, Van Tienhoven A. The effect of thyroidectomy on testicular size and on the photorefractory period in the starling (Sturnus vulgaris L.). J Exp Zool 179: 331-338, 1972.

28. Wilson FE, Follett BK. Plasma and pituitary luteinizing hormone in intact and castrated tree sparrows (Spizella arborea) during a photoinduced gonadal cycle. Gen Comp Endocrinol 23: 82-93, 1974.

29. Yamamura T, Hirunagi K, Ebihara S, Yoshimura T. Seasonal morphological changes in the neuro-glial interaction between gonadotropinreleasing hormone nerve terminals and glial endfeet in Japanese quail. Endocrinology 145: 4264-4267, 2004.

30. Yamamura T, Yasuo S, Hirunagi K, Ebihara S, Yoshimura T. $T_{3}$ implantation mimics photoperiodically reduced encasement of nerve terminals by glial processes in the median eminence of Japanese quail. Cell Tissue Res 324: 175-179, 2006.

31. Yasuo S, Nakao N, Ohkura S, Iigo M, Hagiwara S, Goto A, Ando H, Yamamura T, Watanabe M, Watanabe T, Oda SI, Maeda KI, Lincoln G, Okamura H, Ebihara S, Yoshimura T. Long-day suppressed expression of type 2 deiodinase gene in the mediobasal hypothalamus of the Saanen goat, a short-day breeder: implication for seasonal window of thyroid hormone action on reproductive neuroendocrine axis. Endocrinology 147: 432-440, 2006.

32. Yasuo S, Watanabe M, Nakao N, Takagi T, Follett BK, Ebihara S, Yoshimura T. The reciprocal switching of two thyroid hormone-activating and -inactivating enzyme genes is involved in the photoperiodic gonadal response of Japanese quail. Endocrinology 146: 2551-2554, 2005.

33. Yellon SM, Goldman BD. Photoperiod control of reproductive development in the male Djungarian hamster (Phodopus sungorus). Endocrinology 114: 664-670, 1984.

34. Yoshimura T, Suzuki Y, Makino E, Suzuki T, Kuroiwa A, Mastuda Y, Namikawa T, Ebihara S. Molecular analysis of avian circadian clock genes. Mol Brain Res 78: 207-215, 2000.

35. Yoshimura T, Yasuo S, Watanabe M, Iigo M, Yamamura T, Hirunagi $\mathbf{K}$, Ebihara S. Light-induced hormone conversion of $\mathrm{T}_{4}$ to $\mathrm{T}_{3}$ regulates photoperiodic response of gonads in birds. Nature 426: 178-181, 2003. 